\title{
Bi-resonant structure with piezoelectric PVDF films for energy harvesting from random vibration sources at low frequency
}

\author{
Liang, Shanshan; Crovetto, Andrea; Peng, Zhuoteng; Zhang, Ai; Hansen, Ole; Wang, Mingjiang; Li, \\ Xinxin; Wang, Fei
}

Published in:

Sensors and Actuators A: Physical

Link to article, DOI:

10.1016/j.sna.2016.06.033

Publication date:

2016

Document Version

Peer reviewed version

Link back to DTU Orbit

Citation (APA):

Liang, S., Crovetto, A., Peng, Z., Zhang, A., Hansen, O., Wang, M., Li, X., \& Wang, F. (2016). Bi-resonant structure with piezoelectric PVDF films for energy harvesting from random vibration sources at low frequency. Sensors and Actuators A: Physical, 247, 547-554. https://doi.org/10.1016/j.sna.2016.06.033

\section{General rights}

Copyright and moral rights for the publications made accessible in the public portal are retained by the authors and/or other copyright owners and it is a condition of accessing publications that users recognise and abide by the legal requirements associated with these rights.

- Users may download and print one copy of any publication from the public portal for the purpose of private study or research.

- You may not further distribute the material or use it for any profit-making activity or commercial gain

- You may freely distribute the URL identifying the publication in the public portal 
1

2

3

4

\section{Bi-resonant Structure with Piezoelectric PVDF Films for Energy}

\section{Harvesting from Random Vibration Sources at Low Frequency}

Shanshan Li ${ }^{1,2}$, Andrea Crovetto ${ }^{3}$, Zhuoteng Peng ${ }^{1}$, Ai Zhang ${ }^{1,2}$, Ole Hansen ${ }^{3}$, Mingjiang Wang ${ }^{4}$, Xinxin $\mathrm{Li}^{5}$, and Fei Wang ${ }^{1,2, *}$

${ }^{1}$ Department of Electrical and Electronic Engineering, Southern University of Science and Technology, Shenzhen, China

${ }^{2}$ Shenzhen Key Laboratory of $3^{\text {rd }}$ Generation Semiconductor Devices, Shenzhen, China

${ }^{3}$ Department of Micro- and Nanotechnology, Technical University of Denmark, DTU Nanotech, Building 345E, DK-2800 Kgs Lyngby, Denmark

${ }^{4}$ School of Electronic and Information Engineering, Harbin Institute of Technology Shenzhen Graduate School, Shenzhen 518055, China

${ }^{5}$ State Key Lab of Transducer Technology, Shanghai Institute of Microsystem and Information Technology, Chinese Academy of Sciences, Shanghai 200050, China

*Corresponding author: wangf@sustc.edu.cn

Abstract

This paper reports on a bi-resonant structure of piezoelectric PVDF films energy harvester (PPEH), which consists of two cantilevers with resonant frequencies of 15 $\mathrm{Hz}$ and $22 \mathrm{~Hz}$. With increased acceleration, the vibration amplitudes of the two cantilever-mass structures are increased and collision occurs which causes strong mechanical coupling between the two subsystems. The experimental results show that the operating bandwidth is widened to $14 \mathrm{~Hz}(14 \mathrm{~Hz}-28 \mathrm{~Hz})$ at an acceleration of $9.81 \mathrm{~m} / \mathrm{s}^{2}$, and the peak output power can be $0.35 \mu \mathrm{W}$ at a relatively low operation frequency of $16 \mathrm{~Hz}$. Simulation and experiments with piezoelectric elements show that the energy harvesting device with the bi-resonant structure can generate higher power output than that of the sum of the two separate devices from random vibration sources at low frequency, and hence significantly improves the vibration-toelectricity conversion efficiency by $40 \%-81 \%$. 


\section{Introduction}

With the fast development of the low power wireless sensor networks and the internet of things (IoT), energy harvesting technology has recently attracted a great deal of research interest as a promising technique to replace the traditional batteries [1]. The traditional batteries not only require their costly replacement, especially for sensors at inaccessible locations, but also cause pollution of the environment. Many energy sources from the environment such as light [2], RF radiation [3], thermal gradient [4] and mechanical motions [5-6] can be harvested to provide sustainable power supply to the wireless electronics. The kinetic energy of mechanical vibration is generally the most versatile and ubiquitous ambient energy source [5], and three types of vibrations energy harvesters, electrostatic [7-11], electromagnetic [12-13] and piezoelectric [14-17] have been studied a lot. Piezoelectric energy harvesting devices have been most intensively studied because of their simple configuration, high conversion efficiency and compatible manufacturing process.

To maximize the harvested power output, most of the piezoelectric energy harvesters (PEH) utilize a linear vibrating structure of mass-cantilever system [18], which provides optimal power output at a high resonant frequency (typically larger than $200 \mathrm{~Hz}$ ), as shown in Fig. 1. However, the environmental vibrational frequencies are spectrally distributed and usually below $100 \mathrm{~Hz}$ (especially abundant below $50 \mathrm{~Hz}$ ). Therefore, frequency up-conversion structures are designed to match the ambient excitation [19-20]. Tang et al. [19] demonstrated that by using magnetic repulsion forces to achieve non-contact frequency up-conversion, an average power generation of over $10 \mu \mathrm{W}$ can be achieved within a broad frequency range of 10-22 Hz under 1 $g\left(9.8 \mathrm{~m} / \mathrm{s}^{2}\right)$ acceleration. On the other hand, the traditional PEH has a very limited operating bandwidth nearby its resonant frequency. The performance of the energy harvester will decrease to a large extent when the external excitation frequency shifts away from the resonant frequency of the device. Many efforts have been made to improve the bandwidth of the energy harvesters. Lin et. al. [21] implemented a multi-cantilever piezoelectric generator with current standard MEMS fabrication 
1 techniques, where the resonant frequencies of the device are between $237 \mathrm{~Hz}$ and $2 \quad 244.5 \mathrm{~Hz}$.

3 In this paper, we have developed a polyvinylidene fluoride (PVDF) films based 4 piezoelectric energy harvester $(\mathrm{PPEH})$ with a bi-resonant structure shown in Fig. 5 2(a), which consists of two cantilever-mass systems to achieve two different resonant

6 frequencies. On each of the stainless steel cantilevers, PVDF film is attached to generate electric energy from the stress caused by external vibration sources. The PVDF based polymeric piezoelectric films are used instead of the PZT materials in this demonstration because PVDF is a lead-free polymer material, which is more compatible to the CMOS/MEMS technology. In addition, the PVDF polymer material has lower Young's modulus which can result in lower resonant frequency of the structure [22]. As shown in Fig. 2(c), there is one specific resonant frequency for each beam-mass system. When one of the masses is oscillating at resonance, the vibration amplitude may be large enough to make the mass collide with the other mass and drive the latter into forced vibration mode. Therefore, the latter mass also oscillates to a significant level even though the frequency is off its resonant frequency. By series connection of the circuits of the PPEH-top (PPEH-T) and PPEH-bottom (PPEH-B), the device bandwidth can be widened. In an optimal design, the PPEH with the bi-resonant structure can outperform the sum of the two subsystems in terms of the energy harvested from random vibration sources. It should be noted that this dual resonant structure can also be applied to the other vibrational energy harvesters such as electrostatic or electromagnetic transduction methods [23].

\section{Mechanical model}

Figure 2(b) shows the mechanical model of the device. The mechanical performance of the device can be analyzed under a few basic assumptions:

(1) the magnitude of the mass displacement is small compared to the beam length, so that the "stiffening effect" and the nonlinearity of the beam can be neglected; 
1 (2) the two beam-masses are perfectly aligned, and the collision between them is

2 one-dimensional and elastic with no energy loss;

3 (3) the electromechanical coupling force may be neglected in this device as it is

4 typically small compared to the spring force and the collision force.

5 When no collision $\left(x_{1}-x_{2}+g_{0}>0\right)$ occurs, the governing mechanical equation for the

6 fundamental vibration mode can be written as ( $i=1$ for PPEH-T, $i=2$ for PPEH-B):

$$
m_{i} \ddot{x}_{i}+c_{i} \dot{x}_{i}+k_{i} x_{i}=-m_{i} \ddot{y} \quad\left(x_{1}-x_{2}+g_{0}>0\right)
$$

where $m_{i}$ is the equivalent mass, $c_{i}$ is the equivalent damping coefficient, $k_{i}$ is the spring constant of the beam, $x_{i}(t)$ and $y(t)$ are the displacements of the mass and the external vibration source, respectively. The assumed initial conditions for Eq. (1), are zero displacement and zero velocity, $x_{i}(0)=0$ and $\dot{x}_{i}(0)=0$. When the vibration amplitude is sufficiently large for collisions to occur $\left(x_{1}-x_{2}+g_{0}<0\right)$, the velocities of the two masses must be recalculated. The calculation can be done using conservation of the total momentum and the total kinetic energy:

$$
\sum_{i=1,2} m_{i} u_{i}=\sum_{i=1,2} m_{i} v_{i} ; \quad \sum_{i=1,2} m_{i} u_{i}^{2} / 2=\sum_{i=1,2} m_{i} v_{i}^{2} / 2
$$

where $u_{i}$ and $v_{i}$ are the velocities of the mass before and after the collision, respectively. From Eq. (2), the velocities of the masses after the collision can be calculated:

$$
\begin{aligned}
& v_{1}=\left[u_{1}\left(m_{1}-m_{2}\right)+2 m_{2} u_{2}\right] /\left(m_{1}+m_{2}\right) \\
& v_{2}=\left[u_{2}\left(m_{2}-m_{1}\right)+2 m_{1} u_{1}\right] /\left(m_{1}+m_{2}\right)
\end{aligned}
$$

Therefore, at the moment of collision $\left(t=t_{c}\right)$, the initial conditions for Eq. (1) should be revised to $\dot{x}_{i}\left(t_{c}\right)=v_{i}$.

\section{Simulation}

For the energy harvester with a single resonant structure, a theoretical investigation 
1 has previously been made to study the device performance under a random vibration source [24]. The energy harvester with bi-resonant structure in this paper is more complicated. A numerical calculation with Matlab/Simulink modeling is used with the parameters listed in Table I. Figure 3 shows the Simulink model to study the performance of the bi-resonant structure based on the mechanical equations mentioned above. With an event trigger of zero crossing detection $\left(x_{1}-x_{2}+g_{0}<0\right)$, this Simulink model can detect whether a collision would occur during the energy harvesting process. Figure 4 shows two simulations with different vibration amplitudes. When a vibration source is applied with amplitude of $2 \mathrm{~m} / \mathrm{s}^{2}$ at $20 \mathrm{~Hz}$, there is no collision between the two masses. When the vibration amplitude is increased to $5 \mathrm{~m} / \mathrm{s}^{2}$, collision occurs and the velocities of the two masses are changed after the collision.

With the Simulink model, we can study the frequency response of the device. We calculate the power output against frequency of the bi-resonant structure PPEH with input accelerations of $9.8 \mathrm{~m} / \mathrm{s}^{2}, 14.7 \mathrm{~m} / \mathrm{s}^{2}$ and $19.6 \mathrm{~m} / \mathrm{s}^{2}$. With vibration sources of sinusoidal function, the relationship between the output power and the external excitation frequency in the case of collision is depicted in Fig. 5. When the frequency of the vibration source is tuned from $5 \mathrm{~Hz}$ to $35 \mathrm{~Hz}$, we have seen two peaks of the power output corresponding to the resonant frequencies of $15 \mathrm{~Hz}$ for PPEH-T and $26 \mathrm{~Hz}$ for PPEH-B, respectively. With increased vibration amplitude, the power output is also increased accordingly.

Furthermore, we also calculated the performance of the device under a random vibration source. Figure 6 shows the algorithmic scheme used in the simulation. With a white noise generator and proper frequency filter, we can define various random vibration sources at low frequency to mimic different scenarios in reality. In Fig. 7, we have shown a low-pass filtered random vibration source (cut-off frequency $50 \mathrm{~Hz}$ ) used for the modeling at an RMS acceleration of $10 \mathrm{~m} / \mathrm{s}^{2}$ and the resulting voltage outputs of the devices driven by the vibration. The voltage outputs of the single devices PPEH-T (device 1) and PPEH-B (device 2) are shown 
separately for comparison. The root mean square (RSM) power outputs of the PPEH device with the bi-resonant structure, PPEH-T and PPEH-B single cantilever are shown in Fig. 8, as a function of the RMS acceleration of the random source, respectively. With a RMS vibration amplitude of $20 \mathrm{~m} / \mathrm{s}^{2}$, the RMS power output of the device with bi-resonant structure is calculated to $1.667 \mu \mathrm{W}$, compared to 0.582 $\mu \mathrm{W}$ for PPEH-T and $0.332 \mu \mathrm{W}$ for PPEH-B, respectively. With the bi-resonant structure, therefore, the PPEH device harvests $82 \%$ more power than that of the sum of the two single devices. At accelerations of $3 \mathrm{~m} / \mathrm{s}^{2}, 5 \mathrm{~m} / \mathrm{s}^{2}$ and $10 \mathrm{~m} / \mathrm{s}^{2}$ and $15 \mathrm{~m} / \mathrm{s}^{2}$, the device with bi-resonant structure harvests $75 \%, 66 \%, 77 \%$ and $81 \%$ more power than that of the sum of the two single devices, respectively. This proves that the PPEH device with bi-resonant structure can improve the performance under random vibration sources compared to the single devices.

\section{Experiment}

An experimental PPEH device with bi-resonant structure was fabricated to validate the numerical modeling. As shown in Fig. 2(a), the proposed bi-resonant structure for PPEH comprises of PPEH-T and PPEH-B, both of which consist of a stainless steel beam and a proof mass at the free end. The gap distance $g_{0}$ between the two cantilevers is set to $0.5 \mathrm{~mm}$, which is the minimum gap we can control during the experiment. The length and width of the two cantilevers are $55 \mathrm{~mm}$ and $18 \mathrm{~mm}$, respectively. The thicknesses of PPEH-T and PPEH-B are $0.15 \mathrm{~mm}$ and $0.2 \mathrm{~mm}$, respectively. The proof masses $m_{1}$ and $m_{2}$ are $1.5 \mathrm{~g}$ and $1.2 \mathrm{~g}$. The mechanical quality factor $Q_{m}$ of the stainless beam is estimated to be 10 20. The basic stainless steel beam component consists of a thin film of PVDF based polymeric piezoelectric bonded to a layer of stainless steel. In this paper, PVDF is used instead of conventional piezoelectric materials such as PZT or AlN, because PVDF has a low Young's modulus and comparable electromechanical coupling factor [25], which is more suitable for energy harvesting from low frequency vibration sources. Moreover, PVDF is a lead-free polymer material, which is bio-compatible for application such as energy harvesting from motion of human body. The steel substrates act as 
mechanical supporting layers. The PVDF based polymeric piezoelectric films from Measurement Specialties Inc. USA (MEAS) have silver paste deposited on both sides for electrodes as well as polyester laminations on the electrodes. The effective length, width, and thickness of the PVDF film are designed to be $30 \mathrm{~mm}, 12 \mathrm{~mm}$, and $28 \mu \mathrm{m}$, respectively, which gives a capacitance of $1.38 \mathrm{nF}$.

The two subsystems were connected in series in the measurement setup as shown in Fig. 9 [26-27]. Using a signal generator (Brüel\&Kjær, LAN-XI 3160) and a power amplifier (Brüel\&Kjær, 2719) excitation signals to drive the electrodynamic shaker (Brüel\&Kjær, 4810) are generated; this mimics the vibration sources of interest. An accelerometer is mounted along with the PPEH device to monitor the real time vibration. The signal from the PPEH device is connected to a data acquisition unit through an external load resistance of $20 \mathrm{M} \Omega$, which is the same resistance used in all the following measurement for comparison unless otherwise mentioned.

The single devices with PPEH-T single cantilever and PPEH-B single cantilever are firstly characterized for comparison. Figure 10 and Fig. 11 show the RMS power output of the two devices at different frequency of accelerations at $1.67 \mathrm{~m} / \mathrm{s}^{2}, 3.43$ $\mathrm{m} / \mathrm{s}^{2}, 6.87 \mathrm{~m} / \mathrm{s}^{2}$ and $9.81 \mathrm{~m} / \mathrm{s}^{2}$, respectively. The resonant frequency of the single device 1 (PPEH-T) is $16 \mathrm{~Hz}$ at $1.67 \mathrm{~m} / \mathrm{s}^{2}$. With increased acceleration, the resonant frequency of the single device decreases slightly, which exhibits a "softening effect" similar to the PZT based energy harvester demonstrated in [14]. This is mainly due to the fact that the PVDF film is laminated to a sheet of polyester (Mylar), which is then glue bonded to the stainless steel beam. The lamination and bond quality could be affected by large amplitude of vibration, which decreases the effective Young's modulus of the composite beam. The output power reaches the peak value of 0.55 $\mu \mathrm{W}$ at $9.81 \mathrm{~m} / \mathrm{s}^{2}$ and $14 \mathrm{~Hz}$. The resonant frequency of the single device 2 (PPEH-B) is $22.5 \mathrm{~Hz}$ at $1.67 \mathrm{~m} / \mathrm{s}^{2}$, and its power output reaches the peak value of $0.8 \mu \mathrm{W}$ at $9.81 \mathrm{~m} / \mathrm{s}^{2}$ and $21 \mathrm{~Hz}$.

The RMS output power of the PPEH device as a function of frequency at accelerations of $1.67 \mathrm{~m} / \mathrm{s}^{2}, 3.43 \mathrm{~m} / \mathrm{s}^{2}, 6.87 \mathrm{~m} / \mathrm{s}^{2}$ and $9.81 \mathrm{~m} / \mathrm{s}^{2}$ are shown in Fig. 12. 
1 With increasing acceleration the bandwidth of the PPEH device is continuously

2 widened. The operating bandwidth is increased to $14 \mathrm{~Hz}(14 \mathrm{~Hz}-28 \mathrm{~Hz})$ and the peak

3 output power is $0.35 \mu \mathrm{W}$ at a relatively low operation frequency of $16 \mathrm{~Hz}$ at 9.81

$4 \mathrm{~m} / \mathrm{s}^{2}$. Since the volume of the proof mass is about $0.35 \mathrm{~cm}^{3}$, the harvested power

5 density of the dual resonant device is estimated as $1 \mu \mathrm{W} / \mathrm{cm}^{3}$.

6 Figure 13(a-c) show the spectra of $50 \mathrm{~Hz}$ low pass filtered random vibration sources with RMS accelerations of $5 \mathrm{~m} / \mathrm{s}^{2}, 10 \mathrm{~m} / \mathrm{s}^{2}$ and $15 \mathrm{~m} / \mathrm{s}^{2}$, respectively. During the measurement, the single devices are also tested for comparison. All the measurements are performed with 6.4 seconds per cycle. The typical voltage outputs in one cycle are shown in Fig. 13(d-f).

The average RMS power outputs in 200 test cycles are plotted in Fig. 13(g-i), where the device with bi-resonant structure shows higher harvesting efficiency than the single devices for all the three measurement scenarios. At a RMS acceleration amplitude of $5 \mathrm{~m} / \mathrm{s}^{2}$ the PPEH device with bi-resonant structure generates an average power output of $18.3 \mathrm{nW}$, compared to that of $2.6 \mathrm{nW}$ for device 1 and $7.5 \mathrm{nW}$ for device 2, respectively. At an RMS acceleration amplitude of $10 \mathrm{~m} / \mathrm{s}^{2}$, the PPEH device with bi-resonant structure generates an average power output of $82.9 \mathrm{nW}$, compared to that of $10.9 \mathrm{nW}$ for device 1 and $43.8 \mathrm{nW}$ for device 2, respectively. At an RMS acceleration amplitude of $15 \mathrm{~m} / \mathrm{s}^{2}$ the PPEH device with bi-resonant structure generates an average power output of $0.133 \mu \mathrm{W}$, compared to that of 0.024 $\mu \mathrm{W}$ for device 1 and $0.0708 \mu \mathrm{W}$ for device 2 , respectively. In all three measurement scenarios, higher average power output was harvested from the PPEH device with dual resonant structure than the sum of that from the two separate devices; the power was increased by $81 \%, 52 \%$ and $40 \%$, respectively. The detailed measurement results are listed in Table II. It should be noticed that the measurement results are lower than the simulation we have shown in Fig. 8. This is mainly due to the fact that we have neglected the energy loss during the collision in the simulation and the parasitic capacitance has not been included in the model.

\section{Conclusion}


1 This paper presents the design and experimental characterization of a piezoelectric

2 PVDF films energy harvesting device with bi-resonant structure for wider bandwidth

3 response. Thanks to the two separate resonant frequencies, the vibration amplitudes

4 of two cantilever-mass structures produces strong coupling when colliding at

5 sufficiently large acceleration. With an optimal design of the resonant frequencies of

6 the two subsystems, the energy harvester with bi-resonant structure can provide a

7 decent power output across a broad frequency range. The experimental results show

8 that in this PPEH device, the operating bandwidth can be increased to $14 \mathrm{~Hz}$ (about

$970 \%$ of the central frequency) and the peak value power output is $0.35 \mu \mathrm{W}$ at a

10 relatively low operation frequency of $16 \mathrm{~Hz}$ at $9.81 \mathrm{~m} / \mathrm{s}^{2}$. Both theoretical analysis

11 and experiments have shown that the PPEH device with bi-resonant structure can

12 harvest more energy from random vibration sources at low frequency than the sum

13 of the energy from the separate single devices. Although demonstrated with a

14 piezoelectric device, this dual resonant structure can also be applied to the other

\section{Acknowledgements}

This work is supported by National Natural Science Foundation of China (Project No.: 51505209) and Shenzhen Science and Technology Innovation Committee (Projects No.: JCYJ20150930160634263 and JCYJ20150827165024088). The Shenzhen Key Laboratory of 3rd Generation Semiconductor Devices is supported by Project No.: ZDSYS20140509142721434.

\section{References}

[1] B. E. White, "Energy-harvesting devices: Beyond the battery," Nature Nanotechnology, 3, pp. 71-72, 2008.

[2] K. Sangani, "Power solar - The sun in your pocket," Engineering \& Technology, Vol. 2, No. 8, pp. 36-38, 2007. 
[3] S. Kim, R. Vyas, J. Bito, K. Niotaki, A. Collado, A. Georgiadis, and M. M. Tentzeris, "Ambient RF energy-harvesting technologies for self-sustainable standalone wireless sensor platforms," in Proceedings of the IEEE, Vol. 102, No. 11, pp. 1649-1666, 2014.

[4] R. Venkatasubramanian, C. Watkins, D. Stokes, J. Posthill, and C. Caylor, "Energy harvesting for electronics with thermoelectric devices using nanoscale materials," in IEEE Int. Electron Devices Meeting, pp. 367-370, Dec. 2007.

[5] P. D. Mitcheson, E. M. Yeatman, G. K. Rao, A. S. Holmes, and T. C. Green, "Energy harvesting from human and machine motion for wireless electronic devices," Proceedings of the IEEE, vol. 96, no. 9, pp. 1457-1486, 2008.

[6] S. P. Beeby, M. J. Tudor, and N. M. White, "Energy harvesting vibration sources for microsystems applications," Measurement Science and Technology, vol. 17, p. R175, 2006.

[7] Y. Suzuki, "Recent progress in MEMS electret generator for energy harvesting," IEEJ Transactions on Electrical and Electronic Engineering, vol. 6, no. 2, pp. 101-111, Mar. 2011.

[8] F. Wang, and O. Hansen, "Invisible surface charge pattern on inorganic electrets," IEEE Electron Device Letters, Volume 34, No. 8, pp. 1047-1049, 2013.

[9] F. Wang, C. Bertelsen, G. Skands, T. Pedersen, and O. Hansen, "Reactive ion etching of polymer materials for an energy harvesting device," Microelectronics Engineering, Vol 97, pp. 227-230, 2012.

[10] F. Wang, and O. Hansen, "Electrostatic energy harvesting device with out-of-the-plane gap closing scheme," Sensors and Actuators A - Physical, 211, 131-137, 2014.

[11] H. Lo and Y.-C. Tai, "Parylene-based electret power generators," Journal of Micromechanics and Microengineering, vol. 18, no. 10, pp. 104006-1-104006-8, 2008.

[12] Q. Zhang and E. S. Kim, "Vibration energy harvesting based on magnet and coil arrays for watt-level handheld power source," in Proceedings of the IEEE, Vol. 102, No. 11, pp. 1747-1762, 2014.

[13] M. Wischke, M. Masur, F. Goldschmidtboeing, and P. Woias, "Electromagnetic vibration harvester with piezoelectrically tunable resonance frequency," Journal of Micromechanics and Microengineering, Vol 20, No. 3, 035025 (2010).

[14] R. Xu, A. Lei, C. Dahl-Petersen, K. Hansen, M. Guizzetti, K. Birkelund, et al., "Screen printed PZT/PZT thick film bimorph MEMS cantilever device for vibration energy harvesting," Sensors and Actuators A - Physical, vol. 188, pp. 383-388, Dec. 2012.

[15] Q. C. Tang and X. X. Li, "Two-stage wideband energy harvester driven by multimode coupled vibration”, IEEE/ASME Transactions on Mechatronics, vol. PP, no. 99, pp. 1-7, Jan. 2014.

[16] L. Tang and Y. Yang,"A nonlinear piezoelectric energy harvester with magnetic oscillator," Applied Physics Letters 101, 094102 (2012)

[17] S. Roundy and P. K. Wright, "A piezoelectric vibration based generator for wireless electronics," Smart Materials and Structures, Volume 13, Number 5, 1131 (2004).

[18] A. Crovetto, F. Wang, and O. Hansen, "Modeling and optimization of an electrostatic energy harvesting device," IEEE/ASME Journal of Microelectromechanical Systems, Vol. 23, No. 5, pp. 1141-1155, 2014.

[19] Q. C. Tang, Y. L. Yang, and X. X. Li, "Bi-stable frequency up-conversion piezoelectric energy harvester driven by non-contact magnetic repulsion”, Smart Materials and Structures, vol. 21, no. 12, 125011, Nov. 2011.

[20] H. Kulah and K. Najafi, "Energy scavenging from low-frequency vibrations by using frequency 
up-conversion for wireless sensor applications," IEEE Sensors Journal, 8, 261 (2008).

[21] S. C. Lin, B. S. Lee, W. J. Wu, and C. K. Lee, "Multi-cantilever piezoelectric MEMS generator in energy harvesting," IEEE International Ultrasonics Symposium Proceedings, 755 - 758 (2009).

[22] B. Li, A. Laviage, J. You, and Y. Kim, "Harvesting low-frequency acoustic energy using multiple PVDF beam arrays in quarter-wavelength acoustic resonator," Applied Acoustics, 74, pp. 1271$1278,2013$.

[23] K. Tao, J. Wu, L.H. Tang, N. Wang, S.W. Lye and J.M. Miao, "Broadband energy harvesting using a nonlinear 2DOF MEMS electret-based micro power generator," in the 29th IEEE International Conference on Micro Electro Mechanical Systems (IEEE MEMS 2016), pp. 1236-1239, Shanghai, China, 24-28 Jan., 2016.

[24] E. Halvorsen, "Energy harvesters driven by broadband random vibrations," IEEE/ASME Journal of Microelectromechanical Systems, Vol. 17, No. 5, pp.1061-1071, 2008.

[25] Y.G. Jiang, S. Shiono, H. Hamada, T. Fujita, K. Higuchi, and K. Maenaka, "Low-frequency energy harvesting using a laminated PVDF cantilever with a magnetic mass", Proc. PowerMEMS 2010, pp. 375-378.

[26] A. Crovetto, F. Wang, and O. Hansen, "An electret-based energy harvesting device with a wafer-level fabrication process," Journal of Micromechanics and Microengineering, 23, 114010 (10pp), 2013.

[27] S. Li, Z. Peng, A. Zhang, and F. Wang, "Dual resonant structure for energy harvesting from random vibration sources at low frequency," AIP Advances 6, 015019 (2016). 
Captions:

Figure 1 (a) Schematic view of a piezoelectric energy harvester with a linear system of mass-cantilever structure; (b) frequency response of a typical linear energy harvester with a resonant frequency of $f_{0}$ and bandwidth of $\Delta f$.

Figure 2. (a) Schematic of the bi-resonant structure for PPEH; (b) The mechanical analysis system of the PPEH device with the bi-resonant structure; (c) Frequency response of the energy harvesting devices with single cantilever (left, middle) and the energy harvesting device with bi-resonant cantilevers (right).

Figure 3. Simulink model of the energy harvesting device with bi-resonant structure.

Figure 4. Mechanical performance of the two subsystems when vibration sources with amplitude of (a) $2 \mathrm{~m} / \mathrm{s} 2$ and (b) $5 \mathrm{~m} / \mathrm{s} 2$ are applied at $20 \mathrm{~Hz}$. For $5 \mathrm{~m} / \mathrm{s} 2$, collision occurs during the vibration which changes the velocities of the two mass as shown in the dash zone.

Figure 5. Simulated RMS power output against frequency for the PPEH device with bi-resonant structure at three magnitudes of the acceleration.

Figure 6. Block diagram of the algorithmic scheme used in Matlab/Simulink simulations for the piezoelectric energy harvesting from random vibration source.

Figure 7. (a) Random vibration source through low pass filter $50 \mathrm{~Hz}$ for the energy harvesting modeling of $a_{\mathrm{rms}}=10 \mathrm{~m} / \mathrm{s}^{2}$; (b-d) Calculated voltage output for the energy harvester with bi-resonant structure, single device 1 (PPEH-T) and single device 2 (PPEH-B), respectively; (e) close-up view of the driven vibration source; (f) power spectral density of the vibration source at low frequency.

Figure 8. Simulink results of RSM power outputs against accelerations of PPEH bi-resonant structure, PPEH-T and PPEH-B single cantilever. The subscript B, 1, 2 stand for the device with dual resonant structure, single PPEH-T and single PPEH-B, respectively.

Figure 9. (a) Overview of the measurement setup for the PPEH device; (b) Close-up view of the PPEH device with bi-resonant structure.

Figure 10. Experimental results of RSM power outputs against frequencies of the single device 1 (PPEH-T) with bi-resonant structure of accelerations at $1.67 \mathrm{~m} / \mathrm{s}^{2}$, $3.43 \mathrm{~m} / \mathrm{s}^{2}, 6.87 \mathrm{~m} / \mathrm{s}^{2}$ and $9.81 \mathrm{~m} / \mathrm{s}^{2}$. 
1 Figure 11. Experimental results of RSM power outputs against frequencies of the 2 single device 2 (PPEH-B) with bi-resonant structure of accelerations at $1.67 \mathrm{~m} / \mathrm{s}^{2}$, $3 \quad 3.43 \mathrm{~m} / \mathrm{s}^{2}, 6.87 \mathrm{~m} / \mathrm{s}^{2}$ and $9.81 \mathrm{~m} / \mathrm{s}^{2}$.

4 Figure 12. Experimental results of RSM power outputs against frequencies of the $5 \quad$ PPEH device with bi-resonant structure of accelerations at $1.67 \mathrm{~m} / \mathrm{s}^{2}, 3.43 \mathrm{~m} / \mathrm{s}^{2}, 6.87$ $6 \mathrm{~m} / \mathrm{s}^{2}$ and $9.81 \mathrm{~m} / \mathrm{s}^{2}$.

7 Figure 13. Measurements under low pass filtered $(<50 \mathrm{~Hz})$ random vibration sources 8 with RMS accelerations of $5 \mathrm{~m} / \mathrm{s}^{2}, 10 \mathrm{~m} / \mathrm{s}^{2}$ and $15 \mathrm{~m} / \mathrm{s}^{2}$ (a-c), respectively. The single 9 devices are also tested for comparison. All measurements are performed in 6.4 10 second cycles. Typical voltage outputs in one cycle are shown in (d-f). The average 11 RMS power outputs in 200 test cycles are plotted in (g-i), where the device with 12 bi-resonant structure shows higher harvesting efficiency than the single devices in all 13 three measurement scenarios.

14 TABLE I. Parameters of the energy harvester with dual resonant structure.

15 TABLE II. Vibration sources (low pass filtered $<50 \mathrm{~Hz}$ ) and measurement results of 16 accelerations at $5 \mathrm{~m} / \mathrm{s}^{2}, 10 \mathrm{~m} / \mathrm{s}^{2}$ and $15 \mathrm{~m} / \mathrm{s}^{2}$. 
1 Figure 1 (a) Schematic view of a piezoelectric energy harvester with a linear system 2 of mass-cantilever structure; (b) frequency response of a typical linear energy 3 harvester with a resonant frequency of $f_{0}$ and bandwidth of $\Delta f$.

4

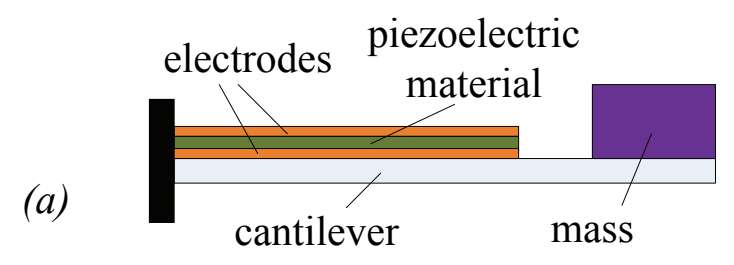

(b)

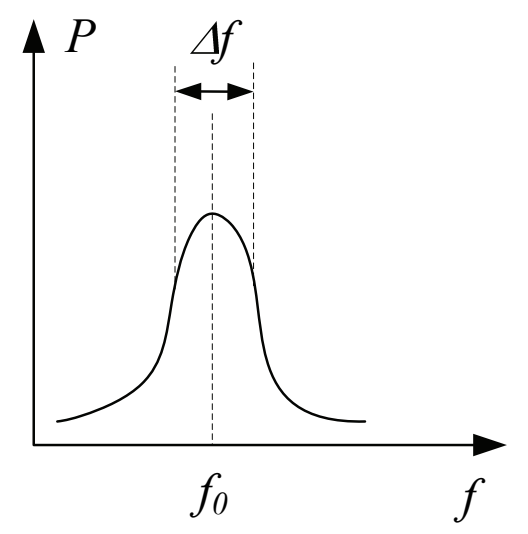


5 Figure 2. (a) Schematic of the bi-resonant structure for PPEH; (b) The mechanical 6 analysis system of the PPEH device with the bi-resonant structure; (c) Frequency 7 response of the energy harvesting devices with single cantilever (left, middle) and 8 the energy harvesting device with bi-resonant cantilevers (right).

7

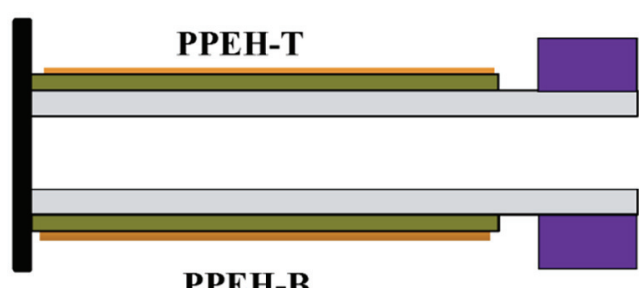

PPEH-B

8

(c)
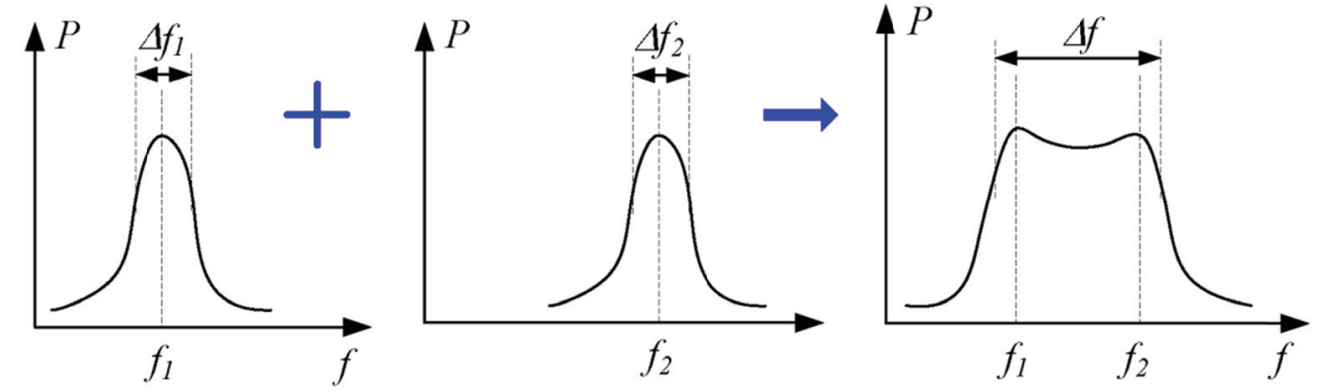

8 
2 Figure 3. Simulink model of the energy harvesting device with bi-resonant structure.

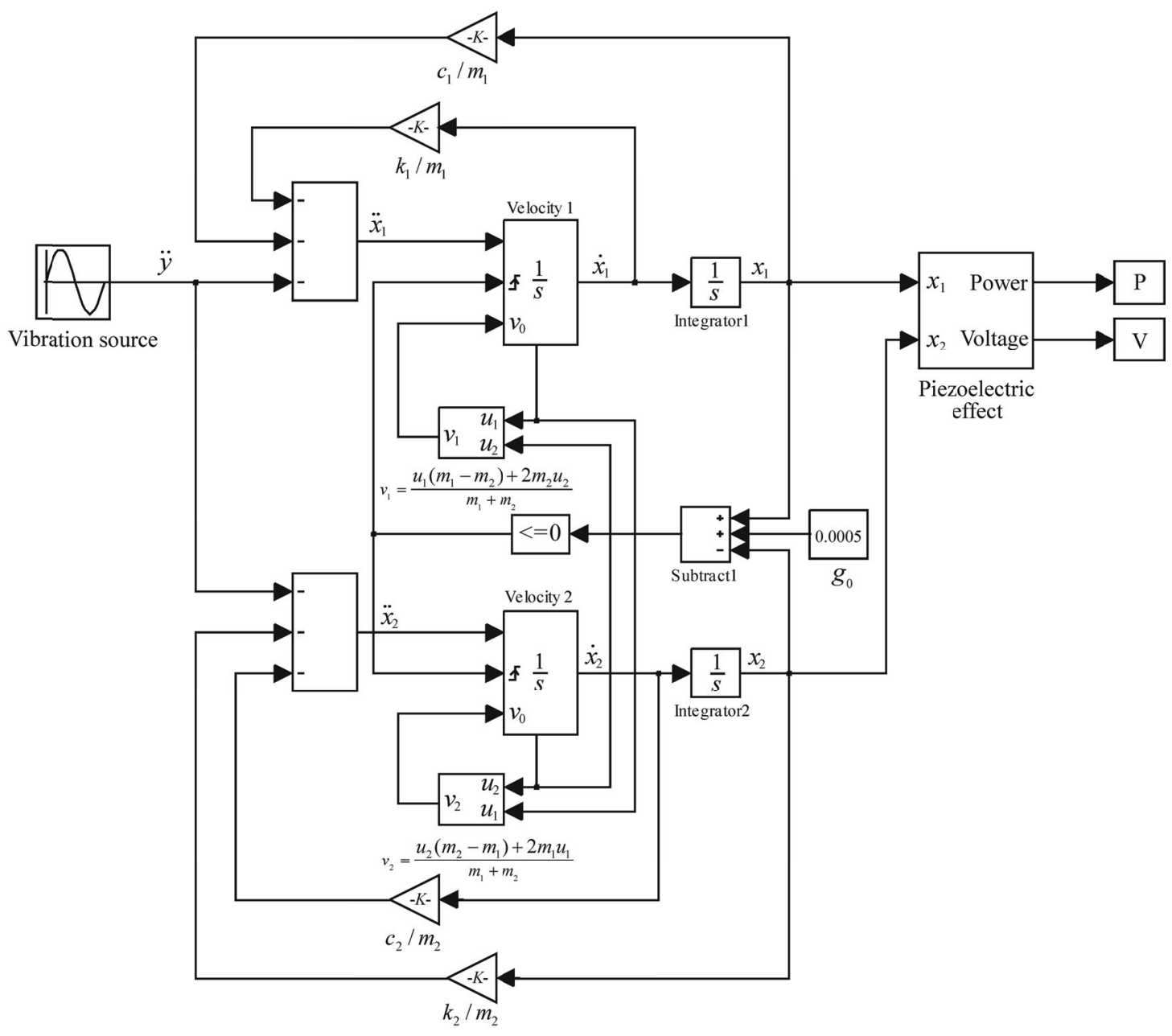


5 Figure 4. Mechanical performance of the two subsystems when vibration sources 6 with amplitude of (a) $2 \mathrm{~m} / \mathrm{s}^{2}$ and (b) $5 \mathrm{~m} / \mathrm{s}^{2}$ are applied at $20 \mathrm{~Hz}$. For $5 \mathrm{~m} / \mathrm{s}^{2}$, collision 7 occurs during the vibration which changes the velocities of the two mass as shown in 8 the dash zone.
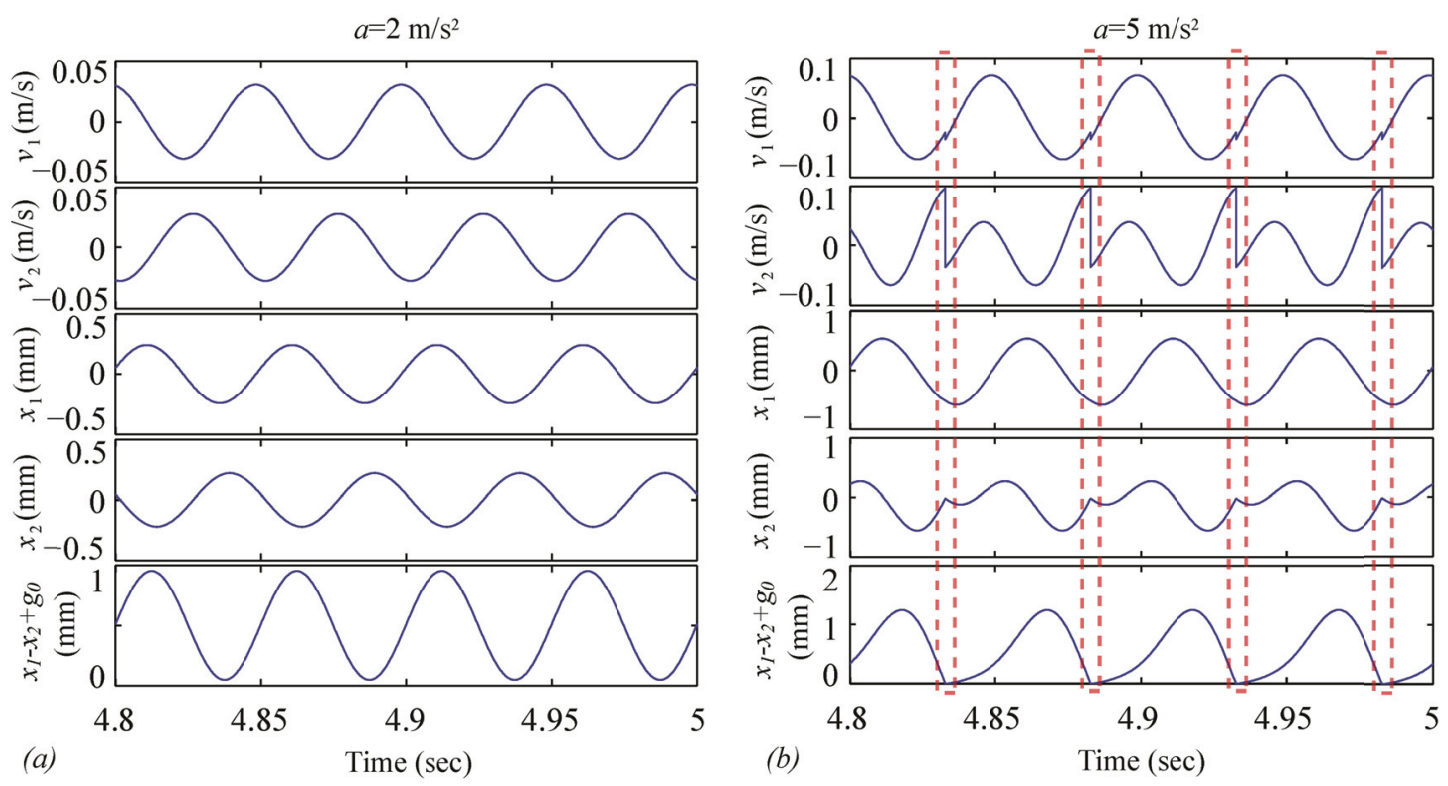
3 Figure 5. Simulated RMS power output against frequency for the PPEH device with 4 bi-resonant structure at three magnitudes of the acceleration.

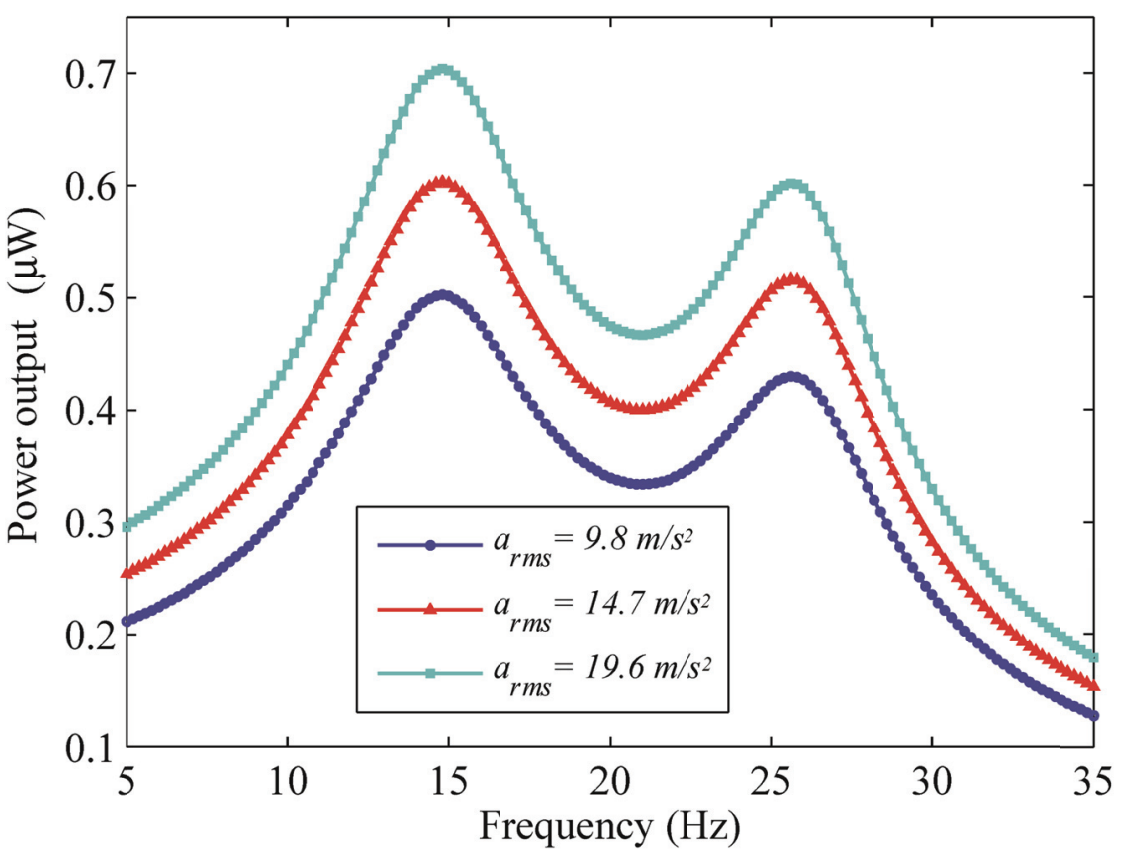

4 
3 Figure 6. Block diagram of the algorithmic scheme used in Matlab/Simulink 4 simulations for the piezoelectric energy harvesting from random vibration source.

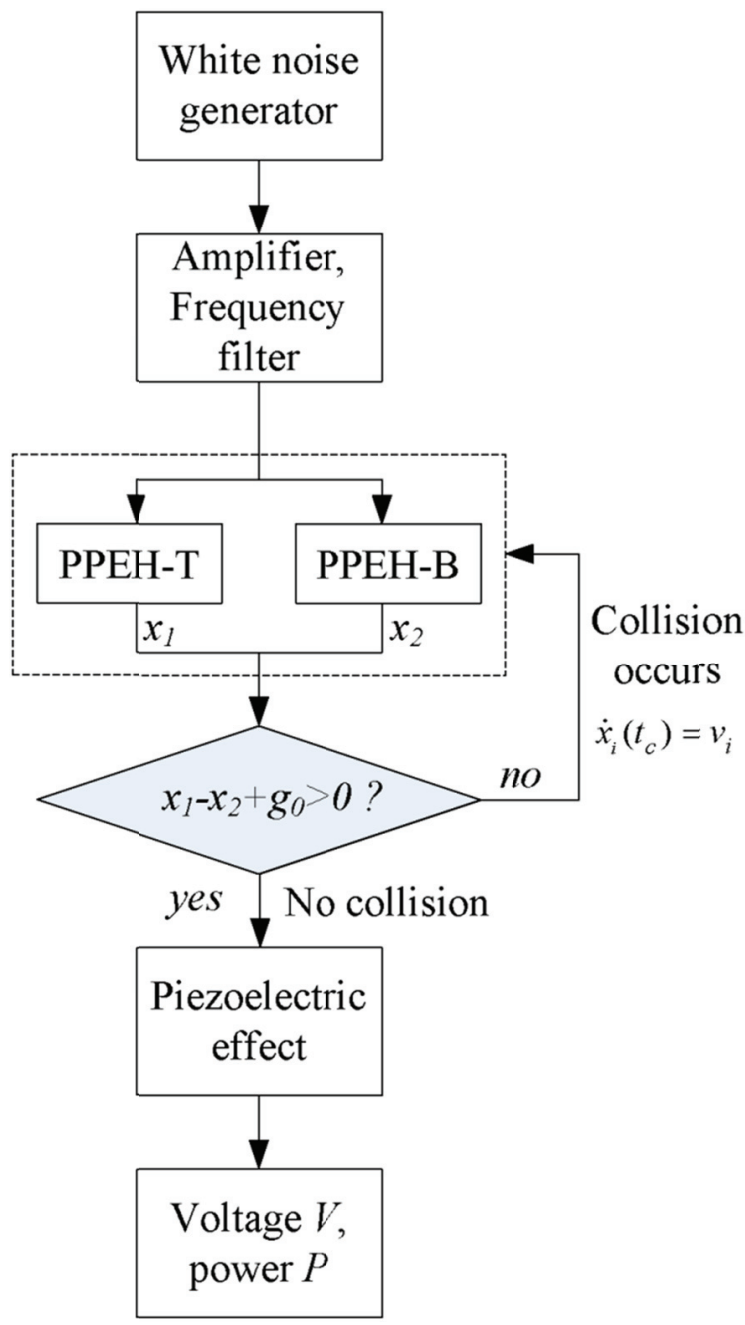


$6 \quad$ Figure 7. (a) Random vibration source through low pass filter $50 \mathrm{~Hz}$ for the energy 7 harvesting modeling of $a_{r m s}=10 \mathrm{~m} / \mathrm{s}^{2}$; (b-d) Calculated voltage output for the energy 8 harvester with bi-resonant structure, single device 1 (PPEH-T) and single device 2 9 (PPEH-B), respectively; (e) close-up view of the driven vibration source; (f) power 10 spectral density of the vibration source at low frequency.

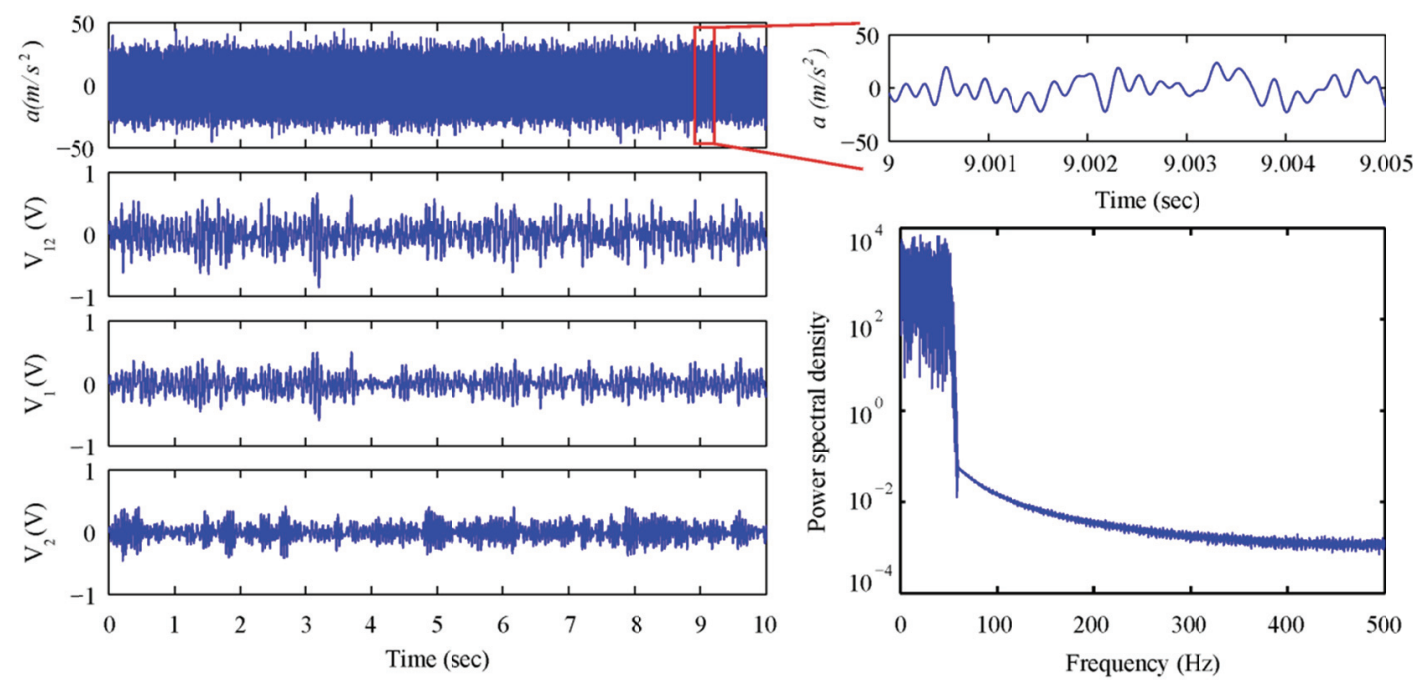


5 Figure 8. Simulink results of RSM power outputs against accelerations of PPEH 6 bi-resonant structure, PPEH-T and PPEH-B single cantilever. The subscript B, 1, 2 7 stand for the device with dual resonant structure, single PPEH-T and single PPEH-B, 8 respectively.

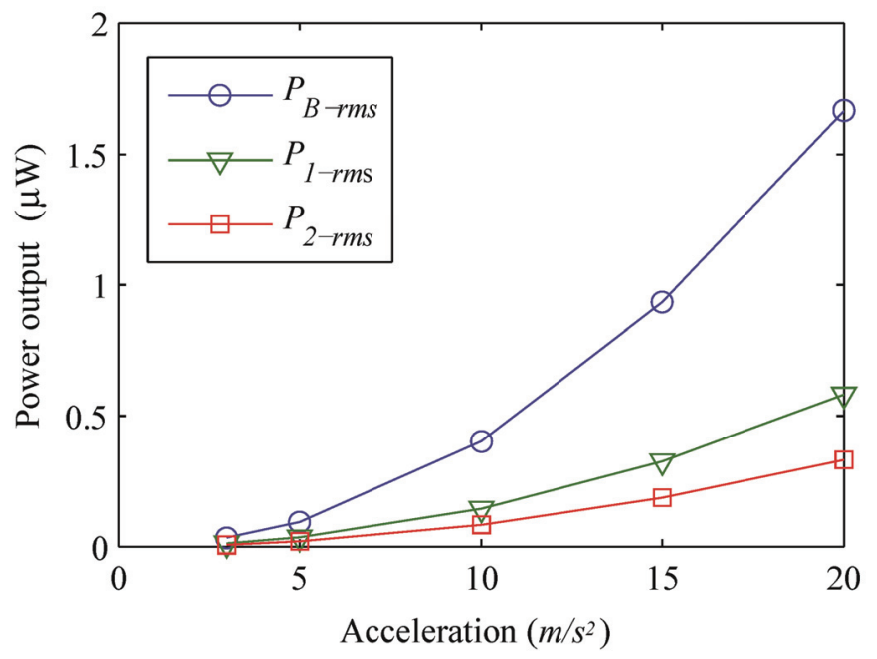

7

8 
3 Figure 9. (a) Overview of the measurement setup for the PPEH device; (b) Close-up 4 view of the PPEH device with bi-resonant structure.

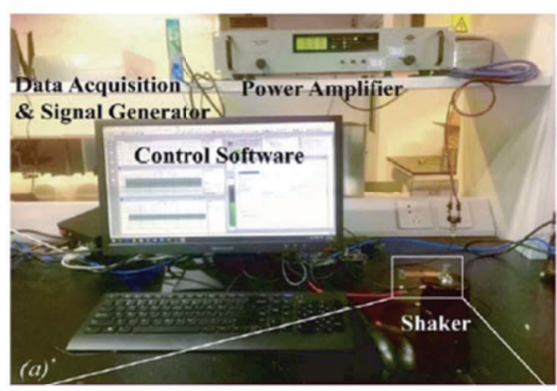

Acceleration

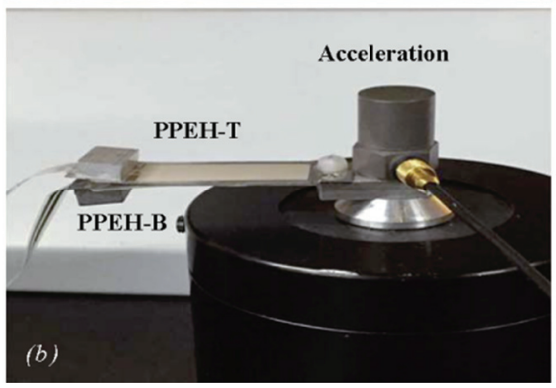

5

6

7

8 
4 Figure 10. Experimental results of RSM power outputs against frequencies of the 5 single device 1 (PPEH-T) with bi-resonant structure of accelerations at $1.67 \mathrm{~m} / \mathrm{s}^{2}$, $6 \quad 3.43 \mathrm{~m} / \mathrm{s}^{2}, 6.87 \mathrm{~m} / \mathrm{s}^{2}$ and $9.81 \mathrm{~m} / \mathrm{s}^{2}$.

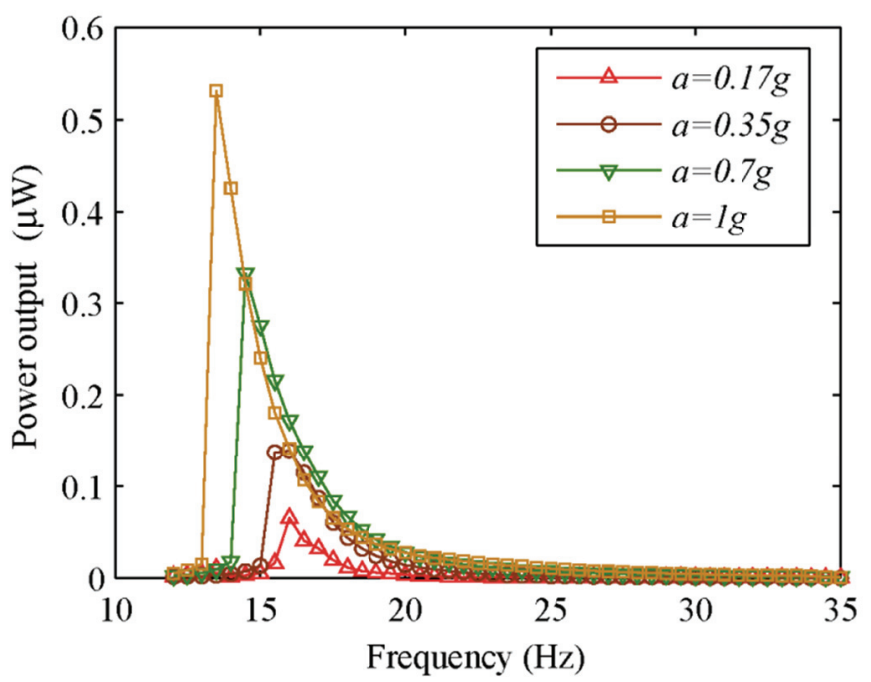

5

6

7 
4 Figure 11. Experimental results of RSM power outputs against frequencies of the 5 single device 2 (PPEH-B) with bi-resonant structure of accelerations at $1.67 \mathrm{~m} / \mathrm{s}^{2}$, $6 \quad 3.43 \mathrm{~m} / \mathrm{s}^{2}, 6.87 \mathrm{~m} / \mathrm{s}^{2}$ and $9.81 \mathrm{~m} / \mathrm{s}^{2}$.

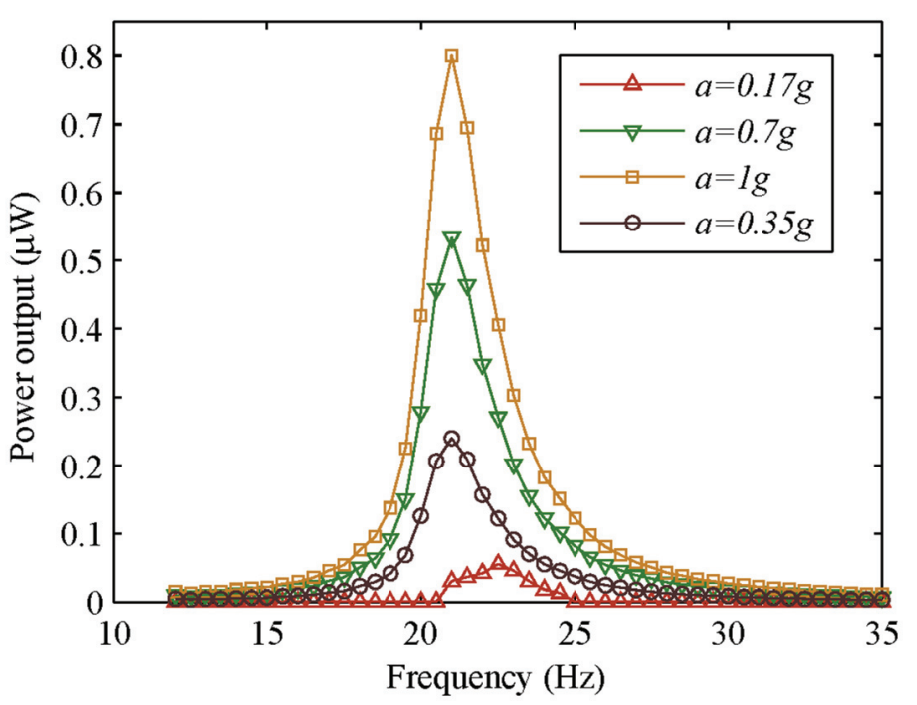

6

7

8 
4 Figure 12. Experimental results of RSM power outputs against frequencies of the 5 PPEH device with bi-resonant structure of accelerations at $1.67 \mathrm{~m} / \mathrm{s}^{2}, 3.43 \mathrm{~m} / \mathrm{s}^{2}, 6.87$ $6 \mathrm{~m} / \mathrm{s}^{2}$ and $9.81 \mathrm{~m} / \mathrm{s}^{2}$.

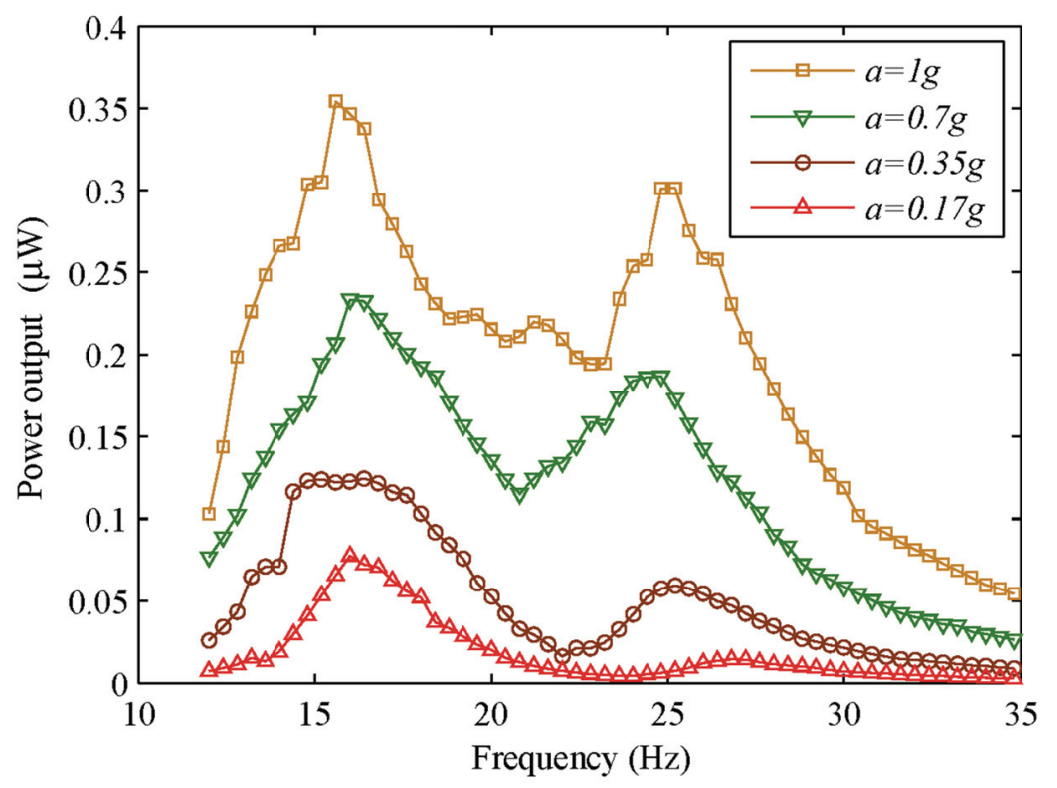

5

6 
8 Figure 13. Measurements under low pass filtered $(<50 \mathrm{~Hz})$ random vibration sources 9 with RMS accelerations of $5 \mathrm{~m} / \mathrm{s}^{2}, 10 \mathrm{~m} / \mathrm{s}^{2}$ and $15 \mathrm{~m} / \mathrm{s}^{2}$ (a-c), respectively. The single 10 devices are also tested for comparison. All measurements are performed in 6.4 second cycles. Typical voltage outputs in one cycle are shown in (d-f). The average RMS power outputs in 200 test cycles are plotted in (g-i), where the device with bi-resonant structure shows higher harvesting efficiency than the single devices in all three measurement scenarios.
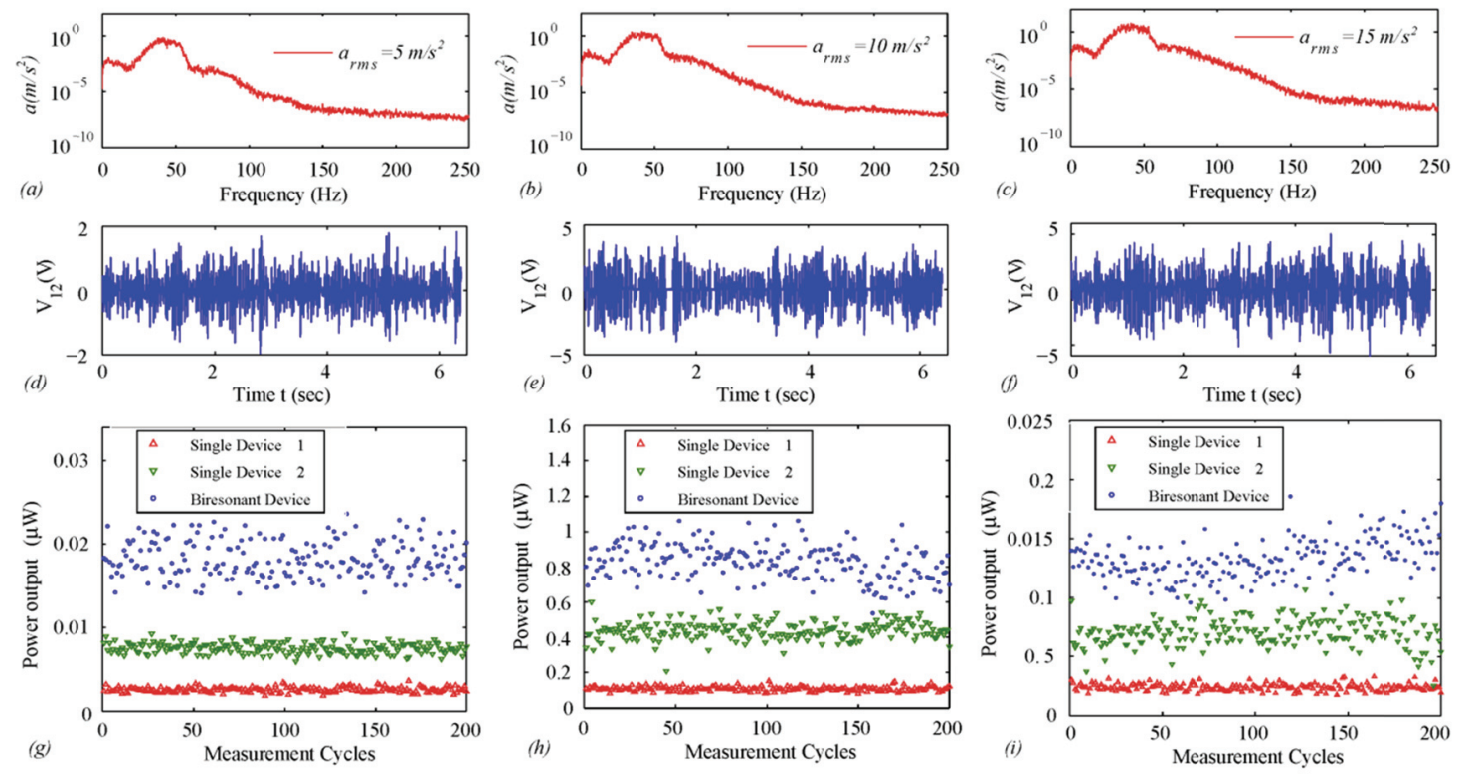
1 TABLE I. Parameters of the energy harvester with dual resonant structure.

2

\begin{tabular}{ccc}
\hline Parameter & Description & Value \\
\hline$m_{1}$ & proof mass 1 & $1.50 \mathrm{gram}$ \\
$m_{2}$ & proof mass 2 & $1.20 \mathrm{gram}$ \\
$k_{1}$ & spring constant 1 & $11.59 \mathrm{~N} / \mathrm{m}$ \\
$k_{2}$ & spring constant 2 & $25.06 \mathrm{~N} / \mathrm{m}$ \\
$c_{1}$ & damping coefficient 1 & $0.022 \mathrm{~kg} / \mathrm{sec}$ \\
$c_{2}$ & damping coefficient 2 & $0.017 \mathrm{~kg} / \mathrm{sec}$ \\
$g_{0}$ & initial gap & $0.5 \mathrm{~mm}$ \\
$d_{31}$ & piezoelectric coefficient & $23 \mathrm{pC} / \mathrm{N}$ \\
\hline \hline
\end{tabular}

3

4 
1 TABLE II. Vibration sources (low pass filtered $<50 \mathrm{~Hz}$ ) and measurement results of 2 accelerations at $5 \mathrm{~m} / \mathrm{s}^{2}, 10 \mathrm{~m} / \mathrm{s}^{2}$ and $15 \mathrm{~m} / \mathrm{s}^{2}$.

3

\begin{tabular}{cccc}
\hline \hline & Source 1 & Source 2 & Source 3 \\
\hline$a_{r m s}$ & $5 \mathrm{~m} / \mathrm{s}^{2}$ & $10 \mathrm{~m} / \mathrm{s}^{2}$ & $15 \mathrm{~m} / \mathrm{s}^{2}$ \\
$V_{B-r m s}$ & $0.603 \mathrm{~V}$ & $1.285 \mathrm{~V}$ & $1.624 \mathrm{~V}$ \\
$P_{B-r m s}$ & $18.3 \mathrm{nW}$ & $82.9 \mathrm{nW}$ & $133 \mathrm{nW}$ \\
$P_{1-r m s}$ & $2.6 \mathrm{nW}$ & $10.9 \mathrm{nW}$ & $24 \mathrm{nW}$ \\
$P_{2-r m s}$ & $7.5 \mathrm{nW}$ & $43.8 \mathrm{nW}$ & $70.8 \mathrm{nW}$ \\
$P_{B-r m s} /\left(P_{1-r m s}+P_{2-r m s}\right)$ & 1.81 & 1.52 & 1.40 \\
\hline \hline
\end{tabular}

4

5 